\title{
QUIROGA, Hugo, (2016), La democracia que no es. Política y sociedad en la Argentina (1983-2016). Buenos Aires: Edhasa. 232 pp.
}

\section{Esteban Iglesias $^{1}$}

El libro reflexiona de forma crítica sobre la dinámica que asumió la política argentina desde el retorno de la democracia, concentrándose en el período posterior a los sucesos que marcaron la crisis política de diciembre de 2001. Tomándolo como principal punto de inflexión, Quiroga analiza al kirchnerismo en tanto fuerza política a lo largo de sus sucesivos gobiernos y las principales iniciativas estatales que desplegó sobre la sociedad. En este sentido, destaca que se ha modificado la «fisonomía» de la democracia argentina, activándose tendencias a la fragmentación partidaria, la preeminencia de los liderazgos e imagen de los candidatos por sobre los programas políticos y la fluctuación del voto. A estas características de las condiciones políticas deben agregarse novedades de relevancia, la ampliación de esfera pública en su terreno digital y los procesos de autorrepresentación por parte de la ciudadanía. De modo que, para el autor, la democracia no puede comprenderse exclusivamente considerando la periodicidad de las elecciones y, ante la abundancia de teorizaciones que enfatizan esto a partir de conceptos tales como «democracia electoral» $\mathrm{O}$ «liderazgos de popularidad», para Quiroga existe una dimensión productivista de la política organizada en torno a la deliberación, la autorrepresentación y el aprovechamiento del espacio público-digital.

Ahora bien, ¿cuáles fueron las principales iniciativas políticas del kirchnerismo en el marco de esta mutación democrática? Para Quiroga, en primer término, la relación del kirchnerismo con las instituciones debe interpretarse en términos de control y utilización en provecho partidario, lo que puede observarse principalmente en las tentativas de controlar la justicia, en especial el Consejo de la Magistratura y la Procuración General de la Nación -mediante la designación de Alejandra Gils Carbó-, así como los organismos de control del Estado como la Fiscalía de Investigaciones Administrativas, la Oficina anticorrupción, la Sindicatura General de la Nación y la Defensoría del Pueblo. En segundo término, el vínculo con el Parlamento se inspiró en el mismo principio evitando en su interior la discusión pública de las principales leyes. En tercer término, se destaca el proyecto cultural del kirchneris-

\footnotetext{
${ }^{1}$ Doctor en Ciencia Política por la Universidad Nacional de Rosario, Investigador del Consejo Nacional de Investigaciones Científicas y Técnicas y profesor en las carreras de Ciencia política de la Universidad Nacional de Rosario y Universidad Nacional del Litoral. Contacto: estebantatiglesias@yahoo.com.ar
} 
mo el que, entre otras cuestiones, implicó el involucramiento de la juventud en las prácticas políticas, esta vez bajo el «relato nacional y popular» y cuya punta de lanza fueronlas políticas de derechos humanos y la creación del canal Encuentro así como las tentativas de partidizar la televisión pública. La iniciativa gubernamental de cancelar el contrato de televisación de los partidos del fútbol argentino a cargo de la empresa Torneos y Competencia y la implementación del «Futbol para todos» sintetiza de forma cabal el interés del gobierno de constituir una opinión pública a su favor.

¿En qué estuvieron inspiradas todas estas acciones políticas? El principal aporte de Quiroga radica en la construcción del concepto de «decisionismo democrático». Si bien el autor lo ha desarrollado en La argentina en emergencia permanente y La república desolada, de 2005 y 2010 respectivamente, en el presente libro lo desarrolla con mayor sistematicidad. Como se sabe, el momento de la decisión es fundamental en la producción de la política y, más precisamente, en la política democrática. De acuerdo con esto, hay que señalar que, en términos teóricos, democracia y decisionismo involucran lógicas de acción política opuestas en la medida en que el primero descansa en el principio de la soberanía popular mientras que el segundo en la de unos pocos. Sin embargo, se han dado diversas soluciones para que ambos términos coexistan desde el liberalismo, el marxismo y el republicanismo durante el siglo XX. Ahora bien, América Latina y Argentina poseen especificidades y particularidades que hay que atender. En este sen- tido, el autor revisa con rigurosidad las teorizaciones de mayor impacto académico, principalmente, la de «democracia delegativa» de Guillermo O'Donnell. Ciertamente, Quiroga realiza un aporte relevante invirtiendo los términos del debate politológico,y en esto intuyo que hay algo de las ideas de José Nun en torno al término «liberalismo democrático», al considerar que el sustantivo es el «decisionismo» y el adjetivo es la «democracia». En efecto, con el «decisionismo democrático» el autor se encuentra en mejores condiciones conceptuales de plantear en qué aspectos y prácticas las democracias realmente existentes son o no democracias evitando un laberinto sobre los diferentes grados de democraticidad del régimen político.

Planteadas las ventajas analíticas del «decisionismo democrático» el autor destaca que este cobra forma en Argentina en 1989 refiriendo a «... una práctica de gobierno ubicada en una zona ambigua e incierta: entre los imperativos de la política y la vigencia del Estado de Derecho» (pág. 26). ¿En qué acciones se manifiesta una práctica que se constituye para el autor en una clave analítica de la política de los últimos treinta años? El uso de decretos de necesidad y urgencia para la implementación políticas públicas, las facultades legislativas delegadas al ejecutivo que nunca fueron reglamentadas en materia tributaria, para la creación de cargos específicos y del Código Aduanero, entre las principales. El contexto que posibilita la emergencia del «decisionismo democrático» se vincula con la declaración y prórroga persistente de la «emergencia pública» por parte del Congreso de la Nación. Entonces, no se trata 
de una práctica de gobierno que se desarrolla al margen de la ley sino, más bien, bajo las características de una «legalidad atenuada».

¿Qué es lo que nos inquieta del concepto «decisionismo democrático»? Entendemos que, planteado así, es un concepto que no contempla los procesos de construcción de las identidades y tradiciones políticas de los actores. En efecto, el autor agrupa, en este concepto, a diferentes figuras políticas, desde Carlos Menem, pasando por Fernando de la Rúa y terminando con Néstor y Cristina Fernández de Kirchner. Entonces, ¿hacia dónde nos conduce este razonamiento? En primer lugar, a pensar que las condiciones políticas, en este caso la «lógica de la emergencia», orienta a los actores a tomar decisiones, generalmente, las mismas. En segundo lugar, a preguntarnos si no hay otros elementos que intervienen en el terreno propio de la decisión, más allá del interés propio y legítimo de aquellos que gobiernan. Así planteadas las cosas, es complicado discernir cómo distintos líderes políticos que poseen diferentes concepciones y prácticas políticas terminan tomando las mismas decisiones. En este sentido, nos encontramos impedidos de sopesar analíticamente la dimensión identitaria del actor político y cuáles son las razones por las que decidió tomar tal o cual curso de acción política, es decir, decisiones.

En definitiva, La democracia que no $e s$, no sólo contiene un título sugestivo ya que nos interpela sobre cómo la clase política y la sociedad mantienen relaciones de conflicto, tensión o apoyo político. En el último ciclo político de la historia argentina, que se abrió luego de diciembre de 2001, La democracia que no es refiere, por un lado, a un modo de funcionamiento de la democracia en la que los ciudadanos no logran relacionarse entre sí ni tampoco con el Estado, donde la separación de poderes está puesta en tela de juicio y la justicia manipulada por el poder ejecutivo, el fomento desde esferas gubernamentales de una cultura política basada en la impunidad y, donde los canales de expresión y opinión pública independiente se mantienen en su mínima expresión. Por otro lado, a un aspecto novedoso de la democracia, que coloca a la política en una dimensión productiva y en pleno desarrollo: los procesos de auto-representación política de la ciudadanía. Se refiere a cuestiones de participación política ciudadana que no se apoya en partidos u organizaciones gremiales para expresar sus peticiones y que, a su vez, lo hace utilizando los medios digitales de comunicación política. Este ámbito de la política se encuentra en pleno desarrollo y no se sabe a ciencia cierta cuáles son sus potencialidades y límites. La democracia se define por sus «horizontes móviles» y gracias a estos fenómenos la sociedad ha podido resignificarla durante los últimos quince años. 